\title{
1. Why justice matters
}

In the poorest countries, people do not need a theory to tell them that there is something wrong with a world in which their children are dying from malnutrition or diseases that could be prevented by relatively inexpensive public health measures. (Brian

Barry, Why Social Justice Matters)

\subsection{INTRODUCTION}

Watch any young child at a birthday party. As the festivities wind up and parents arrive to relieve the exhausted hosts of their exuberant guests, the ritual of handing out the small bags of treats to each departing child unfolds. As long as the child receives his or her bag all is well, and departure occurs smoothly. But if a child misses out, perhaps hurried by a harried parent keen to get going, all hell breaks loose. What a weeping and wailing ensues. This is natural, no one, however young, likes to miss out. But suppose two children leave together and in walking up the driveway to their family vehicles, they should happen to peer into their bags and compare the contents. If one child appears to have more than the other, look out! The next few minutes will be spent by two embarrassed parents trying to hush their progeny and a mortified host rushing to top up the cache of the unfairly deprived child.

As a species, we humans have evolved deep-seated moral sentiments, including intuitive conceptions of fairness and desert. As social animals, those underlying or inherent intuitions are overlaid by conventional norms of 'right behaviour' to one another. Rituals of reciprocity partly define our lived social existence. The moral scope of mutual regard and obligation emanates outward from individual to family to tribe and in complex modern societies to broader planes of ethnic, religious, class and national reach. Successful societies supporting multicultural communities devise ways of allowing different and often conflicting conceptions of the right to coexist, a modus vivendi, if you will. Some relatively limited degree of similarity of values and norms concerning behaviour towards one another only is required - what the political philosopher John Rawls called 'a reasonable overlapping consensus'.

Rawls focuses on nominally liberal democratic societies which support 'a reasonable pluralism'. Such societies exist as exemplars of 'a fair system of 
cooperation' in which a common conception of political justice is more or less accepted by all citizens but from different underlying moral traditions.

Thus. to formulate a realistic idea of a well-ordered society, given the historical conditions of the modern world, we do not say that its public political conception of justice is affirmed by citizens from within the same comprehensive [moral] doctrine. The fact of reasonable pluralism implies that there is no such doctrine, whether fully or partially comprehensive, on which all citizens can or do agree to settle fundamental questions of political justice. Rather, we say that in a well-ordered society the political conception [of justice] is affirmed by what we refer to as a reasonable overlapping consensus. By this we mean that the political conception is supported by the reasonable though opposing religious, philosophical and moral doctrines that gain a significant body of adherents and endure over time from one generation to the next. This is, I believe, the most reasonable basis of political and social unity available to citizens of a democratic society. (Rawls, 2001, p. 32; italics added)

The italicised emphases added in this passage raise interesting questions. First, what does Rawls mean - or what should we take him to mean - by the qualifier 'political' in political justice? Second, what weight are we to place on 'reasonable'? When does the clash of opposing 'moral doctrines' over-step the bounds necessary to anchor a reasonable (workable?) overlapping consensus supporting a stable well-ordered society? Third, what model or picture of democracy has Rawls in mind when he posits the reproduction of a unified, cohesive citizenry? Finally, what 'historical conditions of the modern world' does he have in mind when he seeks to identify a reasonable overlapping consensus?

These are large questions that have exercised the pens and keyboards of political philosophers in the decades since Rawls first proposed his notion of 'justice as fairness' in the 1950s. The discussion developed in this and later chapters makes no claims to great originality but seeks to focus on aspects of the continuing debates that can identify a positive or progressive path to opening up what Keynes in 1930 called 'the economic possibilities for our grandchildren'. This debate assumes special and urgent relevance today as populist reactions to 'multiculturalism' threaten to create or intensify permanent social cleavages based on race and ethnic/nationalist identity, and religion-infused comprehensive moral conceptions of the right are undercutting the foundations of any reasonable overlapping consensus.

\subsection{CONCEIVING JUSTICE}

Taking Rawls's first question - what is a political conception of justice (?) - it is clear that he has in mind a set of social institutions that determine the 'rules of the game' with respect to how laws binding on all citizens and other residents within a territorially defined society are formulated, imposed and their observance monitored. He begins thus: "we start from a conviction that 
a constitutional democratic regime is reasonably just and workable, and worth defending' (Rawls, 2001, p. 27). Rawls then goes on to stress that commitment to democratic regimes or, more broadly to the tenets of political liberalism, runs a fairly narrow sieve over all possible conceptions of justice. Many conceptions will fall well outside any reasonable overlapping consensus of competing comprehensive moral world views. For example, people holding fast to a fundamentalist religiously constituted moral doctrine may favour political institutions that subordinate most forms of political activity to the dictates of a theocratic elite. This provides a provisional answer to the second question. The boundaries of a reasonable overlapping consensus are over-stepped when a particular comprehensive doctrine fails to recognise the legitimacy of the 'actions' of a democratically formed government - or, at least, reserves the right to do so. By actions, I mean the laws, regulations, obligations and decision processes of government.

What is less clear is how Rawls (or anyone) can determine when that line or boundary is crossed. At best, we must say that the boundary is more like a zone or band, with a 'no man's land' of possibilities. How incompatible with the requirements of participation in a democratic political community must a conception of political justice be? It is far from clear that the question can be settled numerically. In other words, how great must the intersection of political conceptions of opposed moral doctrines be for a democratic system of government to cohere, for the centre to hold? In some cases, a workable consensus can emerge with two conceptions supported by roughly equal bodies of citizens. In such cases, a workable modus vivendi is achieved. However, in other circumstances that becomes a recipe for civil war and secession into separate polities. ${ }^{1}$ Rawls's key requirement is for a common political conception - and the social institutions on which it depends - to survive from generation to generation. Otherwise what starts as a former case of mutual acceptance declines into the second case of breakdown, as the mid-nineteenth-century history of the USA attests. At that point, one conception and one set of institutions prevails until a workable modus vivendi emerges. Alternatively, a society dominated by one conception, anchored in a particular comprehensive moral doctrine, may coexist with a number of minority groupings of citizens adhering to radically different moral conceptions. Despite those basic differences, nevertheless, all or most residents in the country accept the legitimacy of the political system and government. ${ }^{2}$ That is, the latter participate in an overlapping consensus,

1 The anthropologist Gregory Bateson (1972) referred to this situation as one of 'symmetrical schismogenesis'.

2 Bateson referred to this situation as one of 'asymmetric schismogenesis', marked by patterned relations of dominance and submission. This dynamic could also degrade into social breakdown. (See my following comments in the text.) 
despite not accepting any deep moral (as opposed to practical or strategic) rationale for so doing. (I'm aware that this stretches Rawls's concept of an overlapping consensus to breaking point, but it does seem to describe the situation pertaining in many countries where strongly antagonistic moral doctrines adhere.) This situation may hold stable through time, even where minority populations are not accorded full citizenship rights. An example might be a democratic society with a predominantly Muslim citizenry that also has a significant minority of citizens professing Buddhist and Christian faiths who actively support the government and its dictates, and in turn are permitted to privately profess their faiths but are not permitted to stand for public office. It is also possible, of course, that the latter situation can change - that is, the overlapping consensus shatter - as supporters of either the dominant group or minority communities reject or challenge the legitimacy of government action. In such cases the overlapping consensus collapses to a singularity. ${ }^{3}$ This is most likely when an apparent overlapping consensus is a strategic compromise based on the overwhelming mobilisation of legitimate force by the dominant group and the balance of power shifts against that group. Other outcomes include the possibility that a minority may be accorded 'local' autonomy over aspects of public action, representation and decision making, based on radically opposed ethnic-national or religious grounds. I have in mind here the situation of the Basque region in Spain and Aceh Province in Indonesia, though as these examples demonstrate in their different ways, the fragility of the 'compromise' over time.

Before turning to the question of why Rawls - and others - holds that social justice matters, it's worth noting the view of another liberal political philosopher, Brian Barry (2005). His chapter heading quote above suggests that questions of social justice are particularly germane to societies that have progressed beyond the state of bare subsistence. In other words, societies of grinding poverty and disease, terrain where the four horsemen of the Apocalypse ride freely, is hardly in need of a theory of justice, at least not in terms of establishing a workable overlapping consensus, as described above. In circumstances of extreme want, the emphasis is likely to be on how to orchestrate paths out of poverty to a situation of basic security. Of course, considerations of justice may place requirements on other societies more fortunately circumstanced, through policies of international aid and the like. This suggests that we need some criteria for deciding when a theory of justice is relevant to underpinning

3 Rawls explicitly recognises the dependence of democracy on a plurality of alternative moral doctrines. 'There is no politically practical way to eliminate this diversity except by the oppressive use of state power to establish a particular comprehensive doctrine and to silence dissent, the fact of oppression' (Rawls, 2001, p. 84). 
social institutions and outcomes. In the case of democratic polities, Rawls argues that we need to establish the appropriate circumstances of justice, the social and economic preconditions that both demand and allow (encourage) the justification of the political arrangements of government.

\subsection{THE CIRCUMSTANCES OF JUSTICE}

What are these circumstances?

We are to think of the circumstances of justice as reflecting the historical conditions under which modern democratic societies exist. These include what we may call the objective circumstances of moderate scarcity and the necessity of social cooperation for all to have a decent standard of life. (Rawls, 2001, p. 84)

Rawls regards alternative but overlapping conceptions of the good as defining a pluralism constituting the subjective circumstances of justice in liberal democratic societies, whereas the existence of moderate scarcity and social cooperation constitute the objective historical circumstances. Without a basic degree of cooperation, the possibility of democracy disappears. Without a degree of - but not too much - scarcity of resources, cooperation is unnecessary. Rawls's focus on scarcity here reflects the influence of mid-twenty-century American economics on political theory. This was a period when market models began to infiltrate other social science disciplines. By then economists had come to accept Lionel Robbins's (1932) definition of 'economic science' as the study of the processes by which and the outcomes of the allocation of scarce resources among alternative (competing) ends. Resources were scarce because the ends were unlimited; any particular end had an opportunity cost - that is, the many other uses of resources that could not be achieved or satisfied. ${ }^{4}$ But scarcity could not be extreme, because as the chapter heading quote suggests, extreme poverty of resources obviates any need for a consideration of justice.

In this conceptual universe, 'ends' were the multifarious ways that individuals satisfied their 'wants'. In most cases freely operating markets routinely took care of matters. Where markets failed to do so, the democratically constituted state could step in and fill the gap. ${ }^{5}$ In keeping with his liberal

4 The influence of mainstream economics on Rawls's theory of justice went well beyond a consideration of the objective circumstances of justice, most particularly with his reliance on aspects of Paretian welfare economics and game theory when discussing the outcome of hypothetical decision making behind the veil of ignorance and, in particular, the derivation of his famous and controversial 'difference principle'.

5 Rawls accepted, largely uncritically, the prevailing doctrines of mid-century American economics and the pluralism of academic political science. In particular, he took for granted the relatively even distribution of power and the economists' assump- 
faith, steeped in the tradition of Kant, John Stuart Mill and Hobhouse, Rawls implicitly adopts an individualistic framework. Cooperation is to be achieved between individuals voluntarily acting as producer/consumers and voters in stable institutional settings underpinned by resilient (partly overlapping) moral commitments.

However, one of the inescapable consequences of a situation of moderate scarcity is that not only cannot all citizens meet (consume) all their desired ends, but they will differ amongst themselves as to how much and how little they can each enjoy. In short, scarcity is relative. Some will experience greater scarcity and its consequences than others. Thus, any theory of justice - whether liberal, conservative or radical - must address the thorny issue of the distribution of the burdens of scarcity. Who wins and who loses? On what grounds? Hence, we also need a theory of distributive justice, one that allocates the benefits and costs of social cooperation as a result of the consequences of resource scarcity. In the case of Rawls's theory of justice as fairness, his two principles of justice, derived from behind 'the veil of ignorance' provides one such solution. There are, of course, alternative theories, some that do not draw on the individualistic conception of political pluralism and the search for 'transcendental' principles that Rawls champions.

It is this possibility that I now turn to.

\subsection{SYSTEMIC INEQUALITY}

Let us begin by positing a society in which power is systematically and effectively distributed unequally. By 'effectively', I mean that this pattern of differences in the capacity to influence government action (or inaction) is so well entrenched that its existence and outcomes are routinely accepted as 'normal' by the vast majority of citizens. By 'systematically', I mean that the power status quo is based in and supported by interlocking sets of institutions in the spheres of government and civil society. Those institutions include formal arrangements of and rules governing social interaction and more informal, normatively charged 'private' patterns of interaction. Into the former fit the various organs of government administration and decision making. The latter include the multifarious and crosscutting regularities of social behaviour conditioned by family, community, business, professional and occupational life, through the processes of primary and secondary socialisation.

tion of the sovereign consumer. In the former case, he ignores the approaches of elite and Marxist theorists on the asymmetric patterned nature of power in capitalist societies; in the latter case, any sense that institutional factors affect or determine consumer 'preferences' - as in the influential contemporary contributions of John Kenneth Galbraith - is beyond the scope of Rawls's frame. 
This model or viewpoint is directly at odds with the individualistic, still less hedonistic, stance of political philosophers who envisage a world made up of human atoms bumping at random into each other in a joint but uncooperative attempt to maximise their individual wellbeing. In parenthesis, one might add that since no one individual has anything like full knowledge of the actual consequences of his or her actions in isolation, the uncertain, unknowable future is likely to continually serve up unexpected and often unwelcome outcomes. This state of chronic uncertainty will itself influence the collective actions of citizens and their rulers. In both democratic and undemocratic polities, the search for security will shape the nature and evolution of the institutions and rules structuring the society more generally. Governments of all stripes retain or lose their rule to the extent that they deliver the basic social resource of security for the bulk of their citizens. Governments also use the fear of insecurity to mobilise mass support, a point I return to later.

It might be argued - and the man himself does so claim - that Rawls is able to neutralise the impact of power inequalities by recourse to his thought experiment, the veil of ignorance. By not allowing the representative agent any foreknowledge of its gender, class or ethnic identity, or even the period or society in which it will dwell, Rawls hopes to remove any impact of power differentials on the collective decision to arrive at generally acceptable principles of justice underlying the ideal polity. The veil of ignorance and the decision-theoretic process by which he derives his nirvana have been the target of a virtual industry of criticism since $A$ Theory of Justice was first published. ${ }^{6}$ But I would argue that this is largely beside the point I wish to make. If Rawls's principles and the institutions expressing them were ever enacted in a world that then gravitated to entrenched power inequalities, however constituted, his ideal republic would crumble, much as Plato and Aristotle feared. It is the realities of power that I hold forms the most basic of the objective circumstances of justice that Rawls and many other political theorists ignore, in a way that Machiavelli, Hobbes and Marx, for example, do not.

We can roughly divide the bases of political inequality into three camps. First, power comes out of 'the barrel of a gun'; that is, military force supports a ruling elite whose final sanction is the deprivation of the lives of its subjects and those of other societies who would challenge its pre-eminence. Second, power is held by a theocratic elite, whose final sanction rests on an ability to bring down the wrath of heaven on the dissident or unbeliever; though of

6 For example, see the early contributions in Blocker and Smith (1978); Wellbank et al. (1982); Barry (1973); Wolff (1977). Much of what passes for contemporary political philosophy over the past 40 years or so has effectively been a debate with Rawls's ghost. Rawls still hovers, Banquo like, at the table of contemporary political philosophy. 
course physical punishment also often accompanies apostasy. Third, power is attached to control of resources necessary to all citizens. In ancient societies this might be a particularly essential and strategic resource like salt or obsidian. In other societies based on military power, it is the control of natural resources like timber, iron and oil that is critical. In capitalist societies, it is control over the means of production and the accumulation of fungible assets that underpin the rule of the dominant class or elite fraction. Of course, the three sources of power interact. Ruling elites will everywhere attempt to co-opt religion and corner resources to impose their authority. Military dictators and their families and close supporters will tend to be wealthy and may also claim semi-divine status. It is not only the early Roman emperors who claimed to be Gods and extracted tribute from subjugated peoples. Theocratic regimes like Saudi Arabia display extreme concentrations of resource ownership and an efficient military force to impose its divinely sanctioned reign. A similar, and in some ways even more extreme situation exists in Iran and Myanmar. In other cases, there will be a real or apparent division of labour among members of the ruling class. In Western capitalist societies politicians, business leaders and religious hierarchies operate in semi-distinct spheres, though not too distinct, since radical disjunctures in policy and ideology threaten the reproduction of the system overall and destroy their dominance in each sphere of power. More authoritarian 'varieties' of capitalism can enforce more direct symbiotic interactions between the spheres of action. Thus, Chinese state capitalism concentrates the organs of government, economy and military force through the central institutional control of the Communist Party and the particular pre-eminence of the Paramount leader. The somewhat more decentralised and chaotic nature of Russian capitalism lies somewhere in the middle, as do some of the smaller authoritarian regimes in central and Eastern Europe.

The expression of power is conditioned by the social institutions of familial, tribal, professional, communal and organisational institutions that differentiate and define particular societies and eras. Ideas and practices of social justice emerge and evolve in specific situations that reflect these objective circumstances. They are not frozen in place and time. Any justificatory theory of justice must recognise and deal with the complexity of the world as it is, while opening sensible discussions about the world as it could be.

What then, we can ask, is the relevance and need for a theory of justice in societies such as those noted in this and the preceding section that display at their centre the objective circumstances of power - the ontology of inequality? ${ }^{7}$

Another way of putting this is: what is the need for a justificatory theory of justice in social worlds in which entrenched power inequalities have shrunk or are likely to shrink the space for a reasonable overlapping consensus, creating a situation 
This, after all, has been a central question in political philosophy from classical times. It has been posed in different ways, but generally gets at the challenge of protecting the citizenry against the excessive power of their rulers.

\subsection{THE ARROW OF TIME}

But before we can directly address this question there is one further objective circumstance, previously hinted at, that must be recognised - namely, the nature and role of what I have termed real time. Political theory (and practice) must deal with the sharp delineation between past, present and future. Citizens and other agents act in the face of limited knowledge of both the past and present. Information about what has happened and what is currently happening is necessarily incomplete for any person or group of people in any concrete instant and place. This follows from the limited perceptual and reasoning faculties of Homo sapiens and the irreversible flow of time. In the latter sense, the present is continuously becoming the past before anyone could possibly capture what is/has happened. But even allowing for those constraints, no one can fully grasp the scope and future outcomes of the complex interplay of individual interactions presently going on; that is, the endless flow of unexpected outcomes at the aggregate level, the fact that the whole is different from the sum of the parts. ${ }^{8}$

Difficulties posed by the arrow of time are raised to a qualitatively different plane when considering the future, the unexplored landscape of open possibilities. Philosophers have sought to establish the basis and limitations of our knowledge of the future. Keynes (1973/1921), beginning with the aim of establishing a purely objective logical basis for probability judgements of future events, effectively and eventually concluded by denying their possibility in any comprehensive sense. Like Chicago economist Frank Knight (1921), he distinguished between 'known unknowns' that captured future randomness with known probabilities - situations of 'risk' - from future randomness with unknown (and unknowable) probabilities - situations of irreducible 'uncer-

of declining or disappearing intersections of alternative extant comprehensive moral doctrines?

8 It is the failure to recognise this fact or circumstance of social ontology that so often results in the fallacy of composition in analyses focused on the individual or representative agent. 
tainty'. ${ }^{9}$ In one of his most quoted passages Keynes (1973/1937, pp. 113-14) states:

By 'uncertain knowledge', let me explain, I do not mean merely to distinguish between what is known for certain from what is only probable. The game of roulette is not subject, in this sense, to uncertainty; nor is the prospect of a victory bond being drawn. Or again, the expectation of life is only slightly uncertain. Even the weather is only moderately uncertain. The sense in which I am using the term is that in which the prospect of a European war is uncertain, or the price of copper and the rate of interest twenty years hence, or the obsolescence of a new invention, or the position of private wealth holders in the social system of 1970. About these matters there is no scientific basis on which to form any calculable probability whatever. We simply do not know.

What this passage hints at is that Keynes, following the extended analysis in his earlier Treatise on Probability, in fact distinguished between three categories of uncertain future outcomes.

First, the relatively limited cases where a full probability distribution can be applied across all possible outcomes. These situations display the character of 'equiprobability', as in 'honest' (unbiased) games of chance or lotteries.

Second, those events that can be judged as less or more likely, the degree of confidence in the judgements varying between people and over time, due to the knowledge, psychological bent and purely contingent factors impinging on those making judgements. The probabilities are based on a more or less adequate data base of past independent events that can be applied to the future occurrence of similar events. This is the territory of the actuary and the basis of the insurance industry. Hence, people are able to insure their houses and their lives, based on probability judgements between fairly narrow limits. ${ }^{10}$ People are also often able to arrive at ordinal (non-numerical, cardinally speaking) relative outcomes that influence their expectations and actions.

9 Both economists came to economics from philosophy, in Keynes's case originally from mathematics. Keynes's Treatise on Probability was completed well before World War I but not published until after the War.

10 This was something that Keynes knew about as he was chair of the board of a large British insurance company for some years. Of course, there are no guarantees here, as the bankruptcy of real-world insurance companies from time to time attests. 'Black swan' events are not as uncommon as the term suggests. On a larger scale, the global financial crisis of 2007-8 provided a near terminal example of unforeseen outcomes and variable interactions that were outside the limits of the probability-based models used to price the underlying financial assets. 
Third, the unknowable but large incidence of cases such as those noted in the quote above about which 'we simply do not know'.

In general, insurance policies exclude a whole range of events whose probability cannot be calculated on the basis of stable historical frequency distributions, that is, because of uncertainty. In society more broadly, an unwillingness to arrive at subjective probabilities in order to decide how to act is the definition of a situation of high uncertainty. [By comparison] the subjective expected utility approach which builds on Ramsey's position does not allow for an unwillingness to place bets. (Dow, 2019, p. 257) ${ }^{11}$

However, in the earlier Treatise, Keynes was at pains to stress another process at work - 'the weight of argument' - that provides support to actions under conditions of both risk and all but irreducible uncertainty.

Weight is positively associated with the amount and extent of the relevant data, $\mathrm{h}$, and provides a measure of the well-foundedness of non-conclusive arguments and hence of the confidence that may be placed in such arguments. Arguments of high weight are based on much information and are well-founded and hence merit high degrees of confidence, regardless of whether their probability is high or low. Arguments of low weight rest on little information, are poorly founded and deserve low degrees of confidence even if their probability is high. All other things being equal, rational agents should choose the argument with the greatest weight. (O’Donnell, 2019, p. 125)

But, events and information about them change and people are prone to sudden revisions of their options and chances. Most areas of future-oriented action must be approached by actions that are, at best, contingent on unexpected, unplanned for outcomes; 'central to his theory of probability was that it was very rare for circumstances to yield a single, correct belief, and that reasoned beliefs could change' (Dow, 2019, p. 256). The future is forever liable to turn

11 The last sentence refers to the work of Keynes's Cambridge contemporary, philosopher Frank Ramsey who suggested that individual utility functions (and hence action) could be constructed from hypothetical lotteries resulting in a 'cardinal' scale of numbers. This led to the expected utility approach and a limited form of cardinal utility analysis in economics. Keynes rejected this approach because it still required probabilities to be assigned to individual outcomes (many unknown) of prospective actions. There is a continuing debate about how much Keynes later came around to accept, at least in part, Ramsey's subjectivist critique (see O'Donnell, 1989; Dow, 1995). Dow (2019, pp. 255-6) claimed that 'Keynes argued that the physical and social worlds are organic, limiting the scope for quantified expectation. Organicism means that the characteristics of objects are not finite, in that relations between them are open to change, and that the laws governing the whole cannot be expected to be the same as those governing the parts.' 
up surprises and uncover what Dow (2019, p. 256) terms new realms of ignorance (see also Runde, 1990).

Eventually Keynes came (in The General Theory of Employment, Interest and Money) to argue that cases of high or chronic uncertainty created the psychological tendency of economic agents to fall back on conventional 'rules of thumb' (now termed 'heuristics' by modern behavioural economists) to enable them to act, though the urge to act was environmentally influenced by the broader state of the world and the level of 'animal spirits' of key decision makers. This was 'rational' in the broad sense, because there was no alternative, given the absence of any adequate classical or subjectivist theory of probability-based action.

Keynes argued that, faced with varying degrees of uncertainty, it is rational to fall back on conventions, stories, rules of thumb, habits, traditions in forming our expectations and deciding how to act. Their function is partly psychological - designed to give a feeling of security, like magic spells or incantations to ward off evil spirits. Talking about 'risk' when one should be talking about 'uncertainty' is a typical 'convention', ubiquitous in company boardroom discussion. We also construct explanations of past events to give us a sense of security in facing the future, which equip us with wrong maps. Generals, it is often said, fight the last war. Governments fight the last recession. However, some updating does take place. Conventions and rules also reflect human learning experience. Without such learning, it would be impossible to make any progress in human affairs. But Keynes emphasised two things. First, learning makes only slow inroads into ignorance and uncertainty. Second, the process is erratic, since the material of learning is subject to unexpected changes. What we learned in one period may become useless in the next. (Skidelsky, 2009 , p. 87$)^{12}$

To face the future is to inevitably confront uncertainty, making for high anxiety and a desire for 'epistemological security', unleashing a search for explanatory and ethical frameworks that bring the future back into some sort of coherent and manageable form. Such a quest is unending and unachievable, other than partially and temporarily. Winston Churchill summarised the inher-

12 The older Keynes's reliance on convention and rules harks back to earlier influences of fellow Cambridge colleagues, philosophers G.E. Moore and Bertrand Russell (Davis, 2019). In the case of the global financial crisis (cf. fn. 10) investors, financial intermediaries, regulators and economists were lulled into a false state of security (complacency) by the conventional use of risk-delineated formal models. Subsequent attempts by mainstream economists to re-write history by recalibrating representative agent models with perfect information gleaned from post-2007 events provide a classic case of Maxwell's genie (cf. fn. 6, previous chapter) at work in seeking to reverse the arrow of time. Twenty-twenty hindsight may soothe the anxieties of the model builders thrown off balance by the force of reality but demonstrate their uselessness in the here and now of policy setting. 
ently limited grasp of human agency as a result of the fluidity of time: 'History unfolds itself by strange and unpredictable paths. We have little control over the future and none at all over the past.'

To sum up, it is the physical nature of the world we inhabit, governed by the second law of thermodynamics and the 'entropic' or 'chaotic' nature of the social world, that makes for an open-ended future and consigns the past to history. Reliance on history as a way of dealing with the future is a clear sign of the high degree of fluidity and anxiety about what might happen next. It may be better than nothing - or, then again, it may not. Assuming path dependence may be the default option, useful over short periods in a high anxiety world. But relying on the continuation of present trends can also lead to disaster when internal contradictions or external shocks disrupt future worlds. ${ }^{13}$

\subsection{ECONOMIC JUSTICE}

It's worth taking a step back to consider the historical context in which concepts of social justice have arisen. MacPherson (1987) has pointed to the emergence of economic justice as an ideal, traceable as far back at least as Aristotle and to the recurring Machiavellian rise and fall cycle of this bifurcated idea, as characterising human societies since the beginning of the mercantile age.

Provisionally then, I define the concept of economic justice by two stipulations: (1) it treats economic relations as having become distinct from social relations in general, and now requiring principles more specific than those of justice in general; and (2) it seeks to impose on economic relations some ethical principle deducible from natural law (or divine law) or from a supposed social nature of man [sic]. (MacPherson, 1987, p. 2)

13 Path dependence is analogous to Newton's first law of motion: a body tends to maintain its motion unless acted upon by another force. In our social world new forces, contingencies and unexpected intersections are always lurking around the corner. The continuous, chaotic 'dance' between openness and path dependence, continuity and contingency, structure and agency, has focused the attention of historians, philosophers and social theorists over the past 50 years. E.P. Thompson (1957) mounted an early contribution to this debate, in the context of a stinging attack on Stalinism following Khrushchev's 'secret speech' denouncing Stalin's excesses in Marxist theory and praxis. Thompson, along with other colleagues on the editorial board of the left-leaning journal Past and Present, argued for the political relevance and possibility of an open future for progress towards socialism. This pre-figured the rise of 'the New Left' a few years later, mining the neo-Hegelian re-reading of Marx. One of Thompson's fellow members of Past and Present, the Australian prehistorian and independent socialist, Vere Gordon Childe, had developed similar ideas (unacknowledged by Thompson), a decade or so earlier (Childe, 1947). See the excellent political biography of Childe by Irving (2020), especially chapters 20 and 21. 
Once market relations came to exert a substantial influence over how society is structured, notions of both commutative and distributive justice became necessary. The first relates to concerns about the 'just price' of commodities 'The just price is that which yields to the producer of each commodity a return proportionate to the status customarily enjoyed by a person of his [sic] occupation or skill' (MacPherson, 1987, p. 6). Existing status relations, rather than market logic governed economic outcomes. This meant that the requirements of distributive justice in an emerging market society were easily met by ensuring that the total output of society was divided in ways that expressed and reinforced the existing status order. This classical view reappeared and was strengthened during medieval times by the Schoolman, notably Thomas Aquinas.

However, as mercantile capitalism began to gather pace in the fifteenth and sixteenth centuries, the ethical force of the older views of economic justice waned. Increasingly, it was the market, defended and promoted by state policy, that became the accepted justification of the use of productive resources and resulting distribution of wealth. Once labour also became a commodity to be bought and sold for wages, economically just outcomes were whatever emerging wages and prices decreed. 'The sway of the market was thus potentially complete; the relative autonomy of the market from society and traditionally imposed norms was assured' (MacPherson, 1987, p. 9). The historical demise of a concept of economic justice centres on the denial that social norms and ethical values should overrule impersonal market forces.

As MacPherson and others have argued, the rise of social democratic theories and movements in the late nineteenth and twentieth centuries resurrected the relevance of distributive justice. The state was looked to as a bulwark against a purely commercial determination of the distribution of the fruits of social cooperation and the operation of the social division of labour. This development was forced by a number of mutually reinforcing factors. First, capitalism itself evolved. With the growth of large corporations exerting control over suppliers and consumers, it could no longer be held that actual market prices ensured equality in exchange and that impersonal market forces ensured efficient outcomes. Not least, it became clear that left to itself the capitalist economy would be prone to recurrent, devastating crises of stagnation and mass unemployment. Second, other institutions emerged to directly challenge the power of capital: trade unions organised labour to demand better wages and conditions. As nascent political democracies appeared, social democratic parties arose to enshrine ethical principles of just distribution and direct entitlements through the legislative acts of government. The tentacles of what the economist John Kenneth Galbraith called 'the sinews of countervailing 
power' constrained the full force of capitalist logic and made space for debates over distributional justice. ${ }^{14}$

MacPherson finishes his historical excursion in the mid-1980s, concluding that the future of economic justice is bleak. Either corporate capitalism will reassert control over and severely limit state intervention aimed at redistributing life chances or a dominant corporate state will overcome the power of the corporations and impose both a progressive redistributive programme and focus attention on 'non-economic' quality of life issues. Either way, the necessity for a theory of economic justice becomes redundant. He hopes for the latter but fears the former. In the decades since he wrote it is the former scenario that appears to have triumphed under the label of neoliberalism. Nevertheless, questions of economic, especially distributive justice have not - as MacPherson believed - withered away. Since the global financial crisis and Great Recession these questions are being posed with a new urgency, once again expressing another turn in the Machiavellian circle. New challenges to the Western democratic model in the current era of global capitalism make it even more critical to develop a workable theory of justice, one fit for our times.

\subsection{REQUIREMENTS FOR A ROBUST THEORY OF JUSTICE}

Not only do we all have to navigate our personal lives in the social and physical world, as it is and is becoming, so too do governments. What ethically grounded theory of social justice might such a world, characterised by the objective and subjective circumstances of justice noted, be offered to guide governments in policy making and demand the political obedience of citizens? Chapters 2 and 3 attempt to put substance on the skeleton presented below.

At base, we need an adequate, robust theory of justice because of the social and economic circumstances of the current phase of global capitalism. Without such a guide, governments and citizens are at the mercy of those forces that currently structure outcomes that prevent large numbers of people from living reasonably secure and fulfilling lives across the planet, and which in light of the deadly simple mechanics of climate change, threaten human existence. The circumstances of justice raise a number of important requirements for any such theory.

14 It is no coincidence that the post-war debates on social justice were sparked in the 1950 s by the early justice as fairness publications of John Rawls. These appeared in the era of 'the affluent society' (another famous term of Galbraith's) marked by the rise of the welfare state and a progressive reduction in economic inequality in the developed economies. 
First, it is assumed in what follows, along with most political philosophers concerned with the justice question, that citizens, regardless of their particular comprehensive moral doctrines, and family, ethnic, religious, gender and class affiliations, have the capacity to recognise the plurality of moral sentiments among their fellows and that this can engender - in the right situations - a binding degree of social cohesiveness, to the extent necessary for government to deliver basic security across that society. Without that basic requirement being met, to quote Margaret Thatcher out of context, 'there is no such thing as society'. Of course, this is not to require all citizens to be so inclined. There will always be individuals who do not possess this capacity, who are 'anti-social' in a literal sense. This form of 'social autism' may be rare but does exist, including in the sphere of government. ${ }^{15}$ More broadly and problematically, there may be groups, circumscribed by religious, familial, regional, racial or class identity that deny the legitimacy of any other group than their own. Members of extreme religious sects offer the clearest case, in the three great world religions. Often such closed groups withdraw and seek to create their own isolated enclaves, where the boundary between insider and outsider is unambiguous and rigorously policed. But a similar dynamic can be seen at the level of family or tribal feuds and even more clearly in a breakdown of civility between regions that results in civil war and a bifurcation into separate polities.

Second, once a basic level of physical security has been delivered, citizens expect a workable distribution of the fruits of social cooperation. This is the challenge of orchestrating a widely accepted theory of distributive justice. This can take many forms but must be able to resonate the moral sentiments of the vast majority of citizens, regardless of their particular circumstances and values. From what has been said, we can expect conflict over the justification of alternative conceptions of just distribution. Even if some agreement over the terms like 'desert', 'entitlement', 'contribution' or 'need' are evident, disagreement re-enters over what this means in practice. There is a case for arguing that the first requirement is 'lexically' prior to the second; that is, that security trumps just distribution, as the chapter headline quote implies. Arguing over distribution of the pie, whatever the recipe, is chimerical when the pie doesn't exist. This was, in effect, the central contribution of Thomas Hobbes, in Leviathan. The problem of order must be solved before that of justice.

15 This is to be distinguished from people who may act as if they don't possess a capacity to recognise the moral basis and limits of action but choose to so act in spite of that understanding. There is a fine line between a narcissist and a sociopath. Some political leaders in the present and the past can exhibit elements of both conditions. 
Third, the existence of structured barriers to action, posed by the extant social institutions of inequality - especially those embedded in class and status position - suggest the imperative to offset disadvantages baked into society at the ground level. This further suggests a non-neutral, interventionist role for government aimed at reducing the impact of the inherited inequalities that reduce the ability of some citizens to realise their conceptions of the good life and surmount the realities of the bad life. Governments that merely administer the public realm simply reinforce the lifespan of long-existing inequalities. Non-government organisations also can have a role in either reinforcing or offsetting unequal life chances. ${ }^{16}$

Finally, the quest for greater distributive justice has a temporal dimension. A just distribution of the goods and bads of social cohesion and cooperation is an ongoing challenge and one that faces the open uncertainties thrown up as the present becomes the future. Intervention by government and non-government actors attempting to deliver security and overcome inequality are liable to result in unexpected outcomes and opportunities as new sources of knowledge and ignorance become apparent. The price of justice is eternal vigilance.

All this strongly implies that an acceptable theory of justice must be built upon a consequentialist ethical platform, that governments and other organised institutional processes should have to take into account (become aware of) the actual outcomes of their decisions and non-decisions, as they become evident. Hence, they must actively monitor, recognise and respond to unexpected outcomes that impinge on actual capacities of citizens to realise their (individual and collective) goals. This last imperative, as noted, follows from the open, organic nature of the uncertain future. This is not to argue that considerations of human (and other species') rights are irrelevant, rather that the weight to be given to particular rights in real-world circumstances should be determined by the extent to which their recognition and promotion result in good (or reduce bad) outcomes. This leaves open for debate and revision what the defining characteristics of 'good' and 'bad' are. ${ }^{17}$ However, to anticipate the argument, there is likely to be, in many cases faced by government and civil society organisations, a basic asymmetry. Reducing existing structural barriers to more equal life chances will normally trump measures to promote life chances for those groups already well advantaged. In short, removing 'bads' beats promoting 'goods'! The 'rights' of the well-off are not absolute.

16 Of course, NGOs can also do the reverse, as the plethora of right-wing think tanks and front organisations funded by billionaires amply demonstrate in Trump's America.

17 I have argued in favour of a 'comprehensive consequentialist' over a deontological 'rights-based' theory of justice in Berry (2017, chapter 9). 
In summary, justice matters because the structures of social life generate and perpetuate unequal life chances to enjoy secure, dignified and flourishing lives in all societies and at all times and places. Although the future is open and radically uncertain, path dependence at the macro-social level tends to perpetuate inequalities unless social forces challenge and change them. A robust discussion over, and development of strategies in, the economic, political and cultural realms can inform progressive forces for change. 